\title{
quelques exemples d'utilisations spécifiques des géotextiles
}

\author{
E. LEDEUIL \\ Ingénieur Arts et Métiers, \\ Docteur en Mécanique des Sols \\ Membre C.F.G.G. (1)
}

Suite de Photos (diapos) présentée à la réunion du 18 mars 1985

au Comitê Français de Mécanique des Sols et des fondations

Dans le cadre de l'amênagement hydroélectrique de Ferrières-sur-Ariège réalisé par Electricité de France, plusieurs utilisations spécifiques de géotextiles ont été faites. Les photos qui suivent ont été présentées en "bref » avec quelques commentaires, mais elles parlent d'elles-mêmes. Elles montrent la diversité et la souplesse d'emploi des géotextiles et particulièrement en stabilisateur de matériaux.

La première série traite de protection de berge à l'aide de doubles panneaux de tissus (polypropylène) injectés de béton. Ces panneaux font $5 \mathrm{~m}$ de large à vide et les écailles formées sont posées avec chevauchement directement sur les enrochements à stabiliser (photo 6). Le remplissage en béton suspendu (photo 2) permet la pose même sous l'eau.

Il convenait de stabiliser le pied d'une falaise morajnique. Les remblais nécessaires rétrécissant la vallée, devaient être protégés en pied des érosions dues aux augmentations des vitesses surtout en période de crues (photos 1 et 3 ).

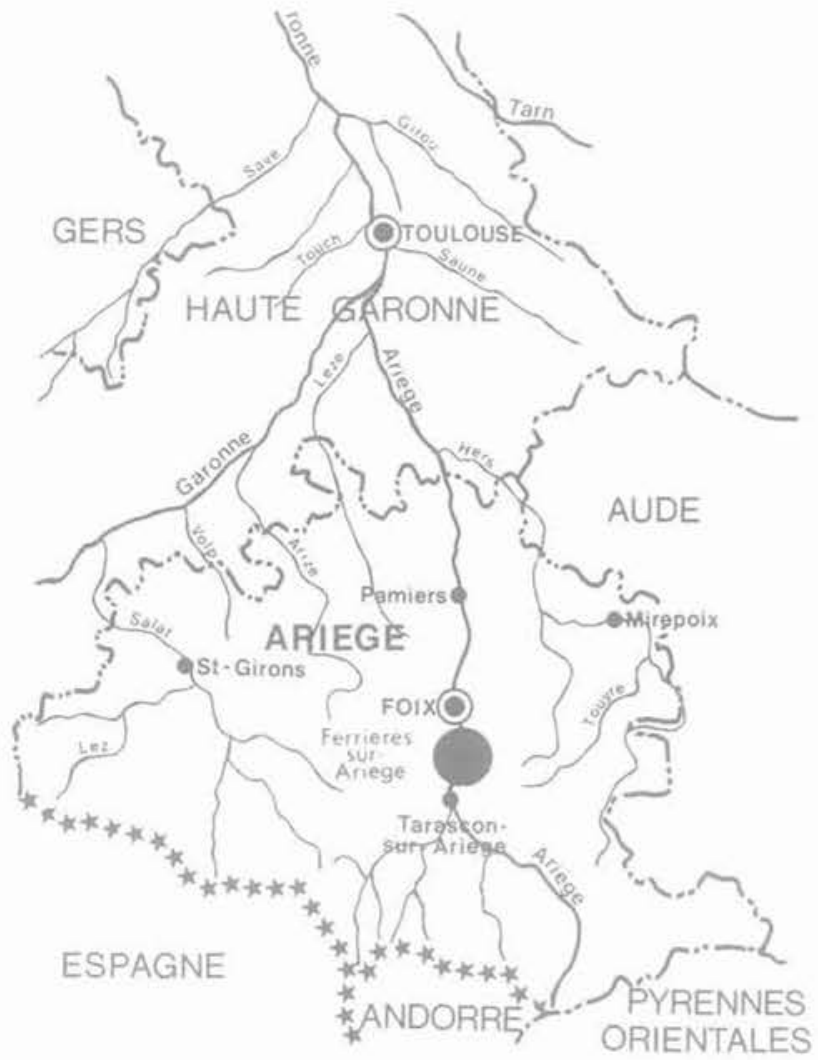

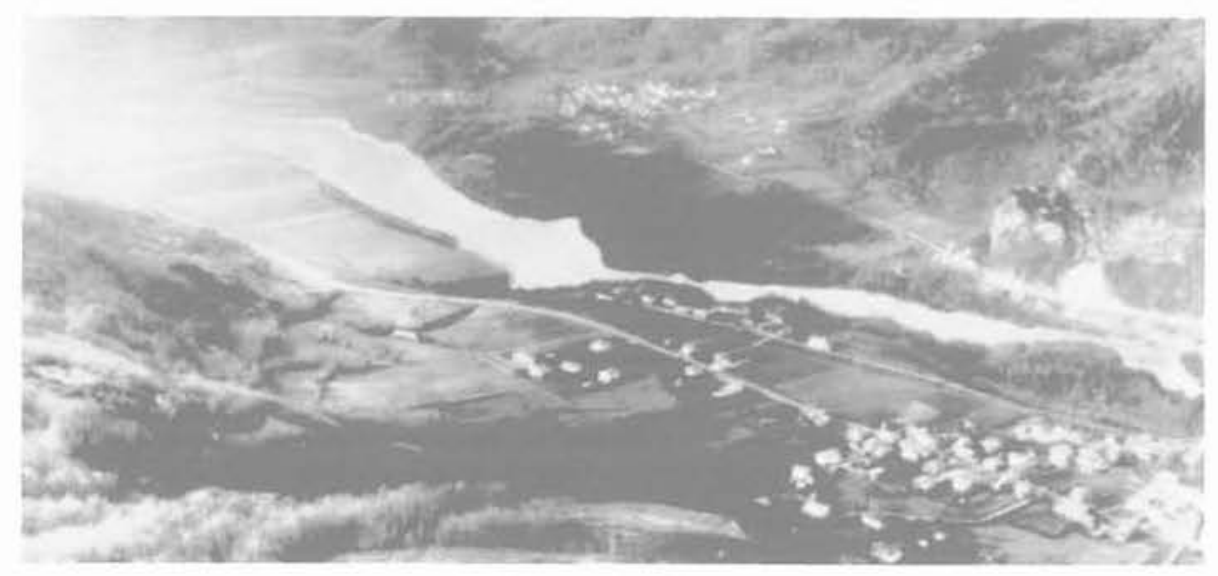

Aménagement E.D.F. de Ferrières (barrage de Garrabet et son lac)

(1) C.F.G.G. - Comité Français des Géotextiles et Gẽomembranes. 


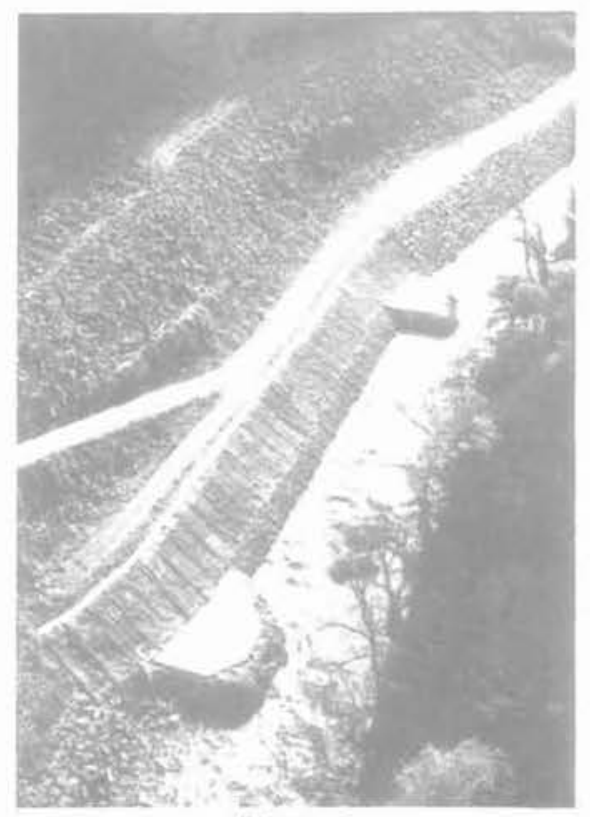

Photo 1

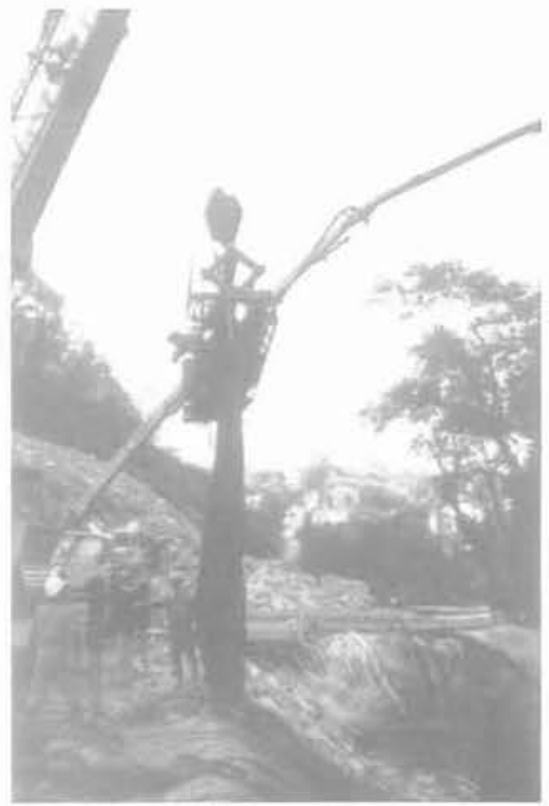

Photo 2

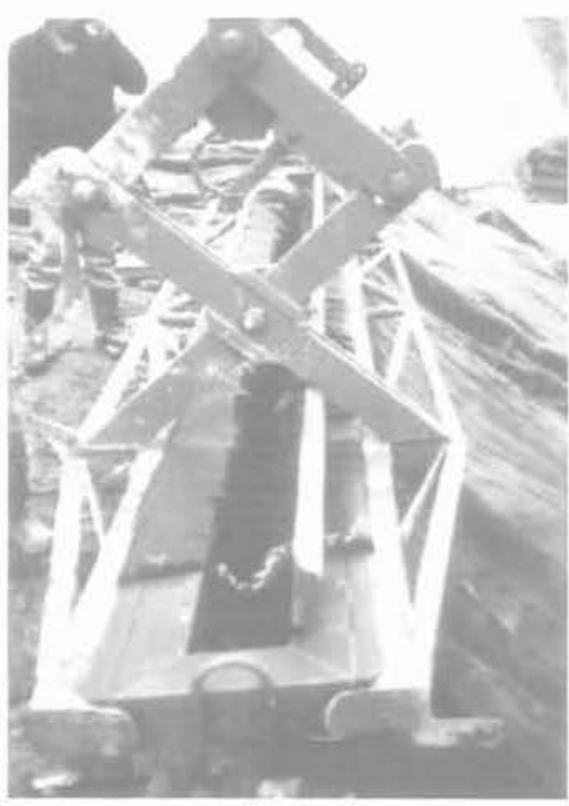

Photo 4

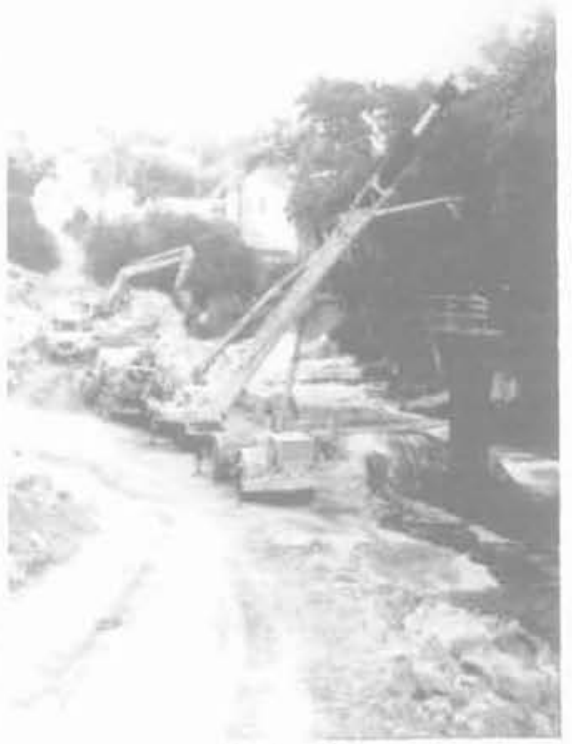

Photo 5

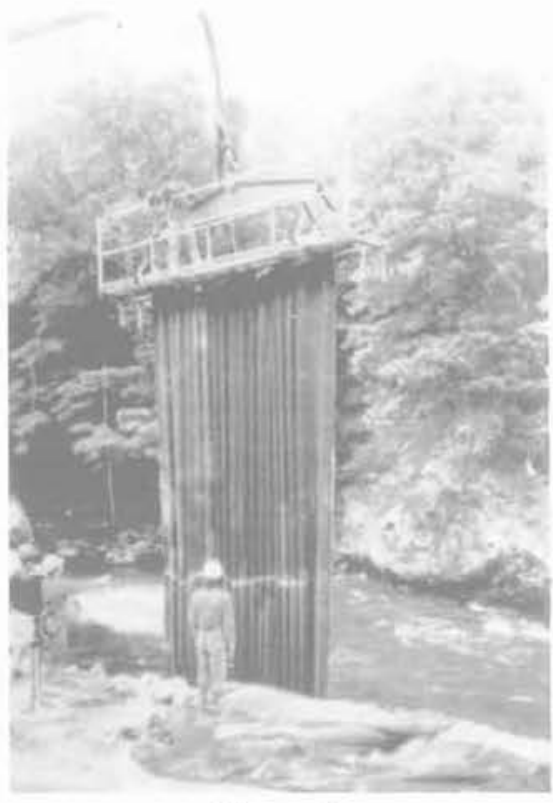

Photo 6

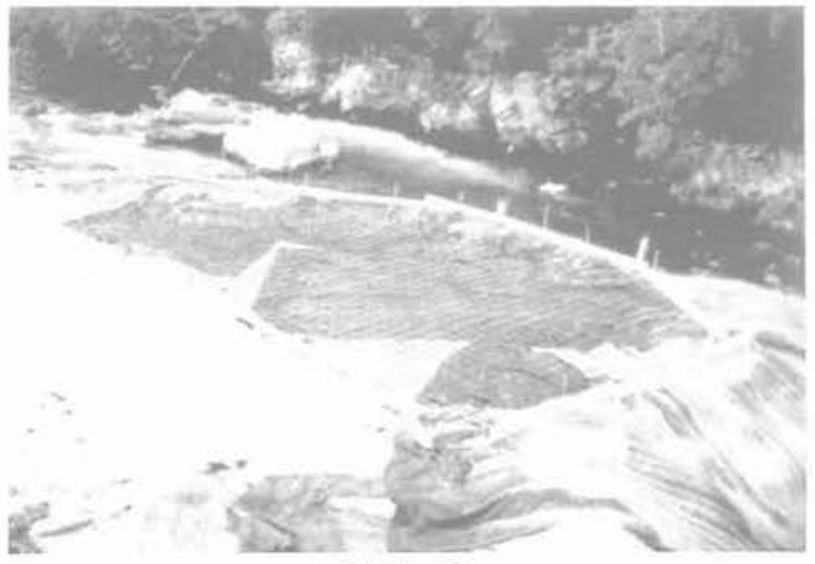

Photo 9

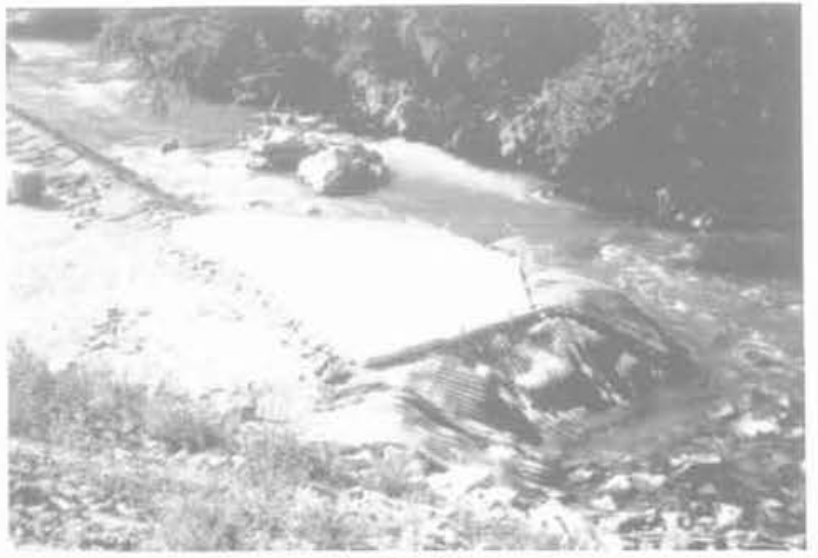

Photo 10 


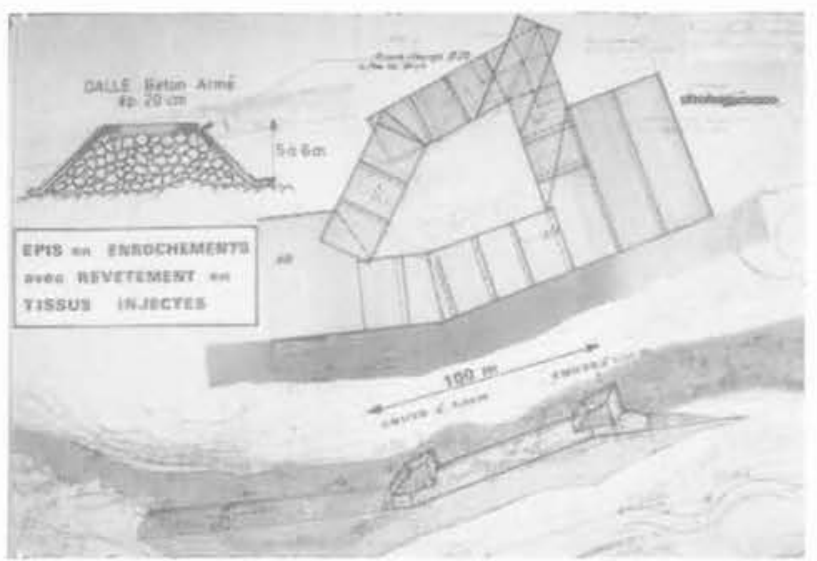

Photo 3

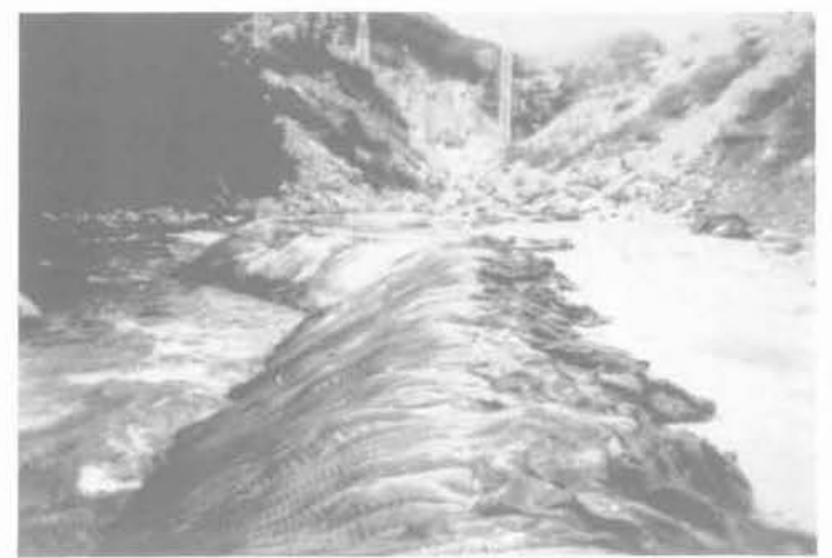

Photo 7

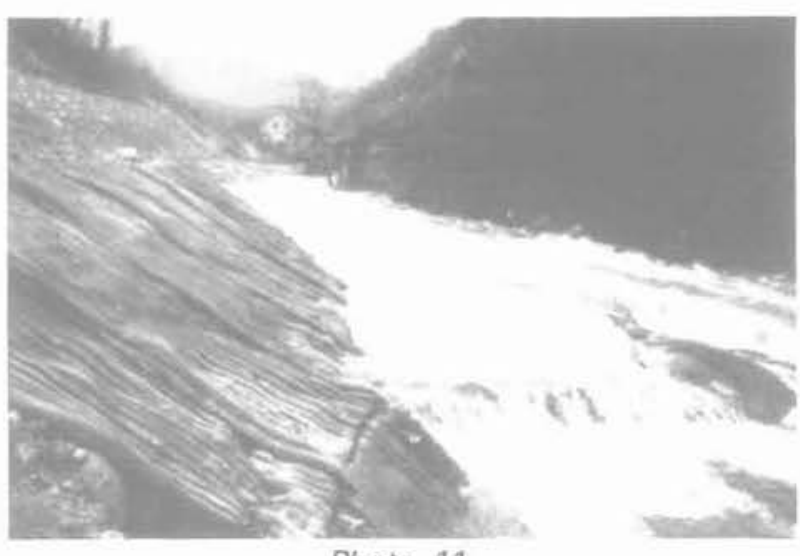

Photo 11

Le canal amont entre les deux seuils est aussi protégé de tissus injectés de bêton (photos $1,7,8$ et 11).
Afin de contrôler les vitesses, deux seuils ont été réalisés directement dans la rivière, sans dérivation des eaux (photo 3).

La réalisation des seuils en enrochements protégés en surface par des panneaux de tissus injectés de béton a été faite par Chantiers Modernes avec Prodireg en ce qui concerne les tissus et leur mise en place par palonnier (photos 2 et 4 ) et pompe à béton (photos $2,5$ et 6$)$.

En surface une dalle en béton armé solidarise les têtes des tissus (photos 9 et 10) avec des cannes d'ancrage enfoncées dans le béton frais.

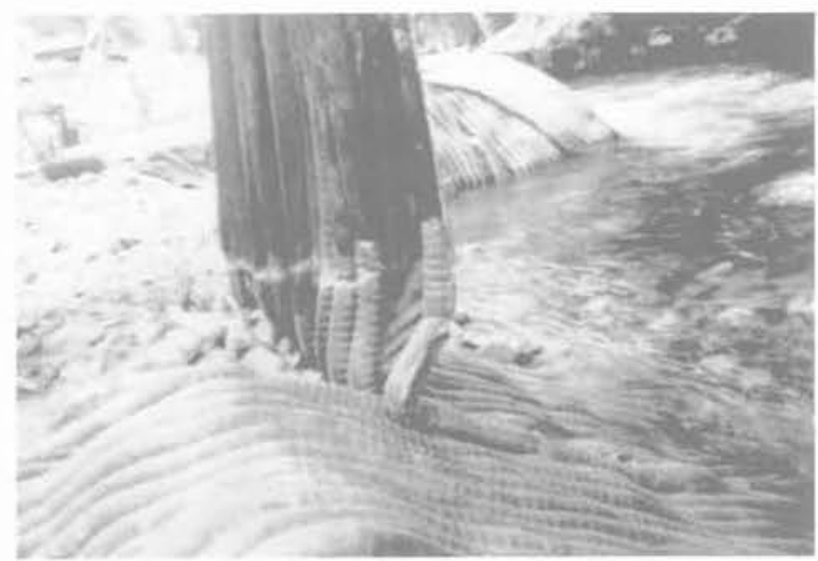

Photo 8

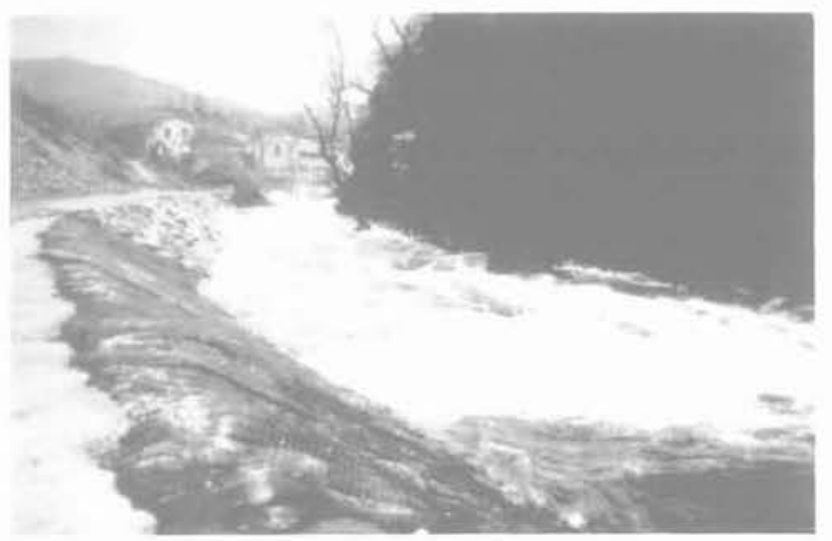

Photo 12

Les seuils créés en rivière sont incomplets (permettant une réalisation dans l'eau sans trop de problème) mais donnent en période de crue (photos 11 et 12) le rendement d'un seuil complet. 


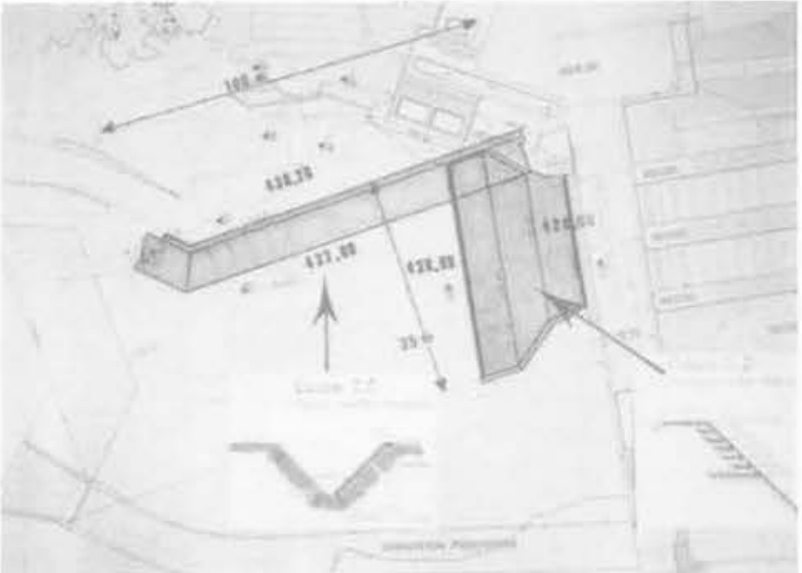

Photo 13

Devant le barrage (seuil à 432,80 ) le batardeau est à la cote 438 , les installations de bétonnage sont prévues sur ce batardeau.

Une protection de l'installation de bétonnage placée devant la prise d'eau a été réalisée à l'intérieur du batardeau en terre par des panneaux de tissus injectés de béton. Cette protection en cas de destruction du batardeau par submersion (comme en 1982) conserverait la station de bétonnage en place, et elle sera dégagée par la suite et servira de berge au chenal d'entonnement du barrage (photos 14 et 15). Le batardeau a aussi êté protégé par tissus sur son aval pour résister à une légère submersion (photo 13 ã droite).

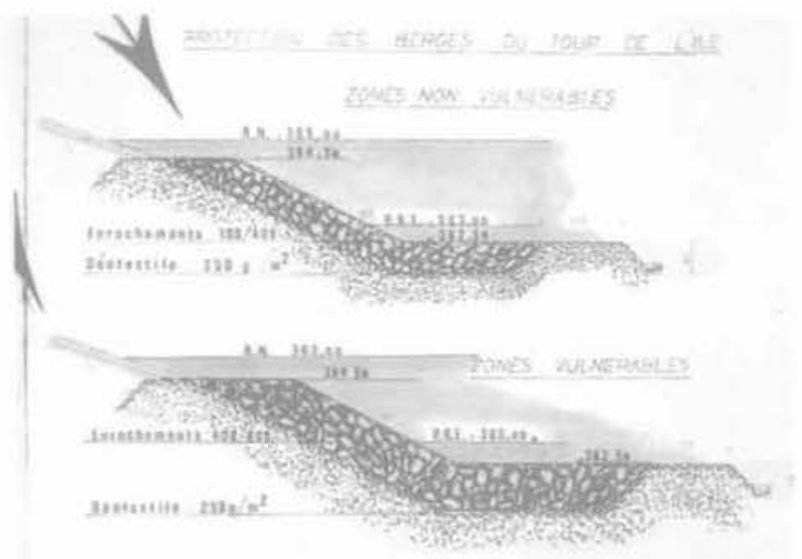

Photo 20

Pour la mise en eau du barrage le batardage de la dérivation provisoire est prévu en flot vif avec des palplanches Larsen $V$ de $11 \mathrm{~m}$ de haut mais un prébatardage capable de diminuer le débit à couper devait réhausser les eaux de 430 à 434,20 afin de faire passer $40 \mathrm{~m}^{3} / \mathrm{s}$ sur le barrage.

Une toile «Jumbo * de chez Robusta a été demandée à Prodireg (polypropylène tissé avec fil inox de $80 \mathrm{t} / \mathrm{m}$ de résistance à la rupture). Correctement ancrée elle devait pouvoir jouer ce rôle (photo 16).

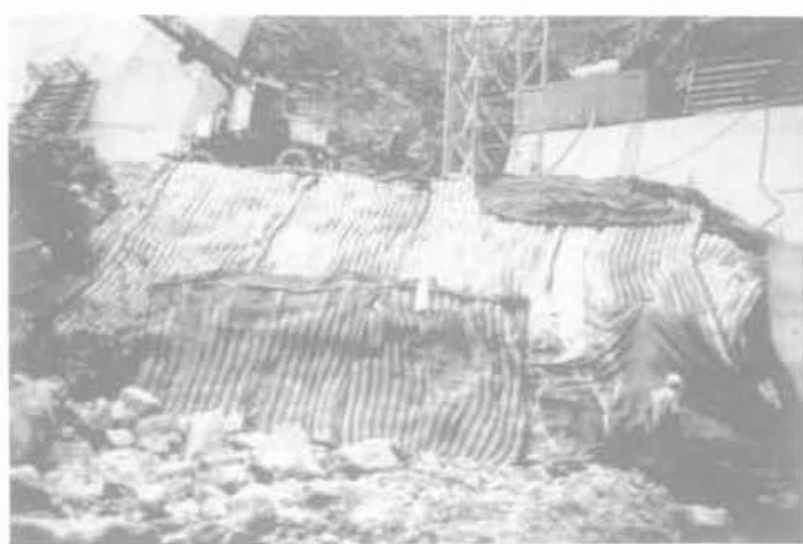

Photo 14

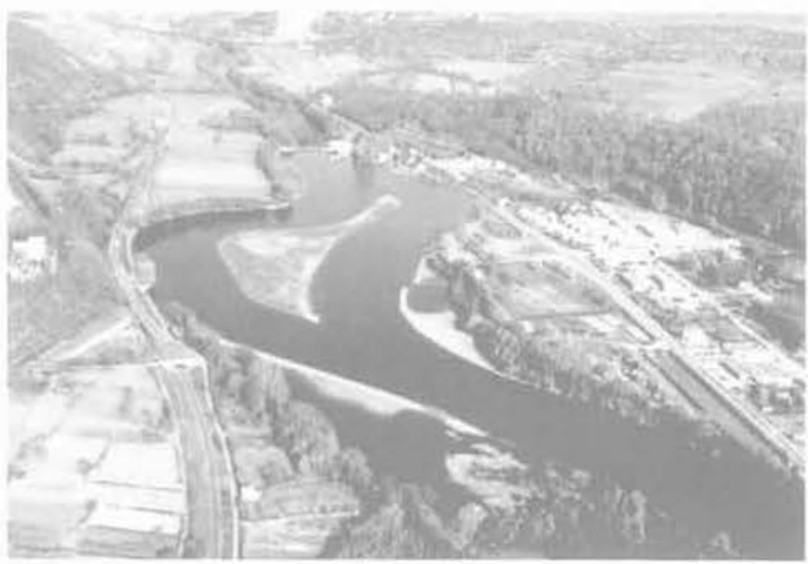

Photo 17

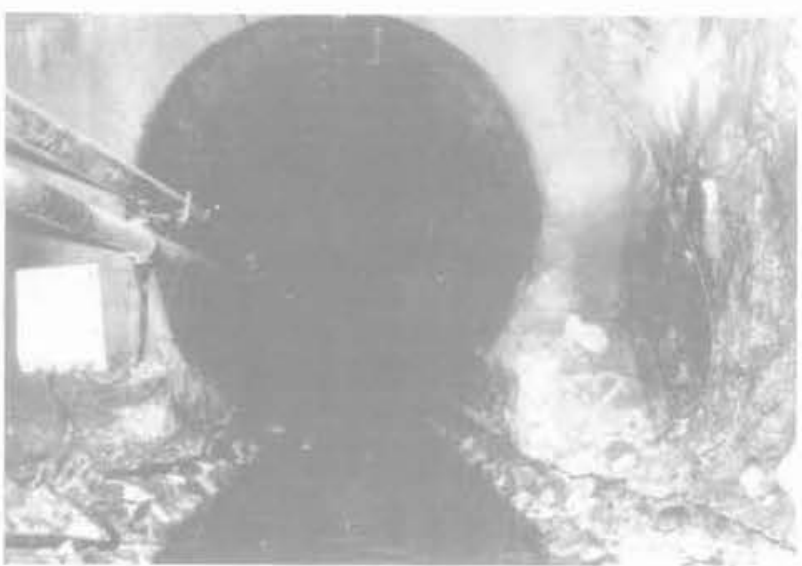

Photo 21

Pour l'utiliser en lac de compensation le réservoir de Labarre (photo 17) en aval de Foix devait disposer de $400000 \mathrm{~m}^{3}$ de volume sur $2 \mathrm{~m}$ de hauteur. Son envasement était tel qu'il a fallu curer et les matériaux indésirables ont alors été stockés dans une île dont on a dû créer $1700 \mathrm{~m}$ de berges stables (photo 20) avant de combler le centre. Des aménagements complémentaires, quai (photo 19) ou seuil (photo 18) ont aussi consommé des géotextiles. 

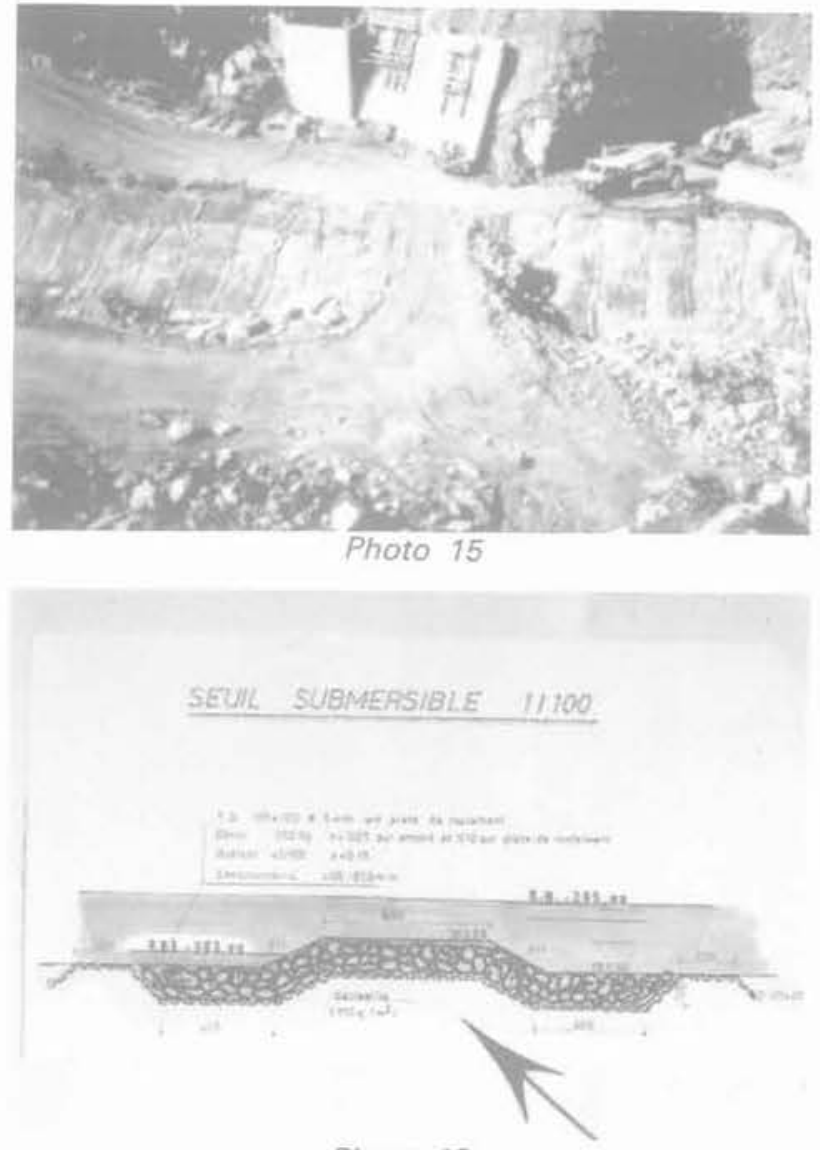

Photo 18
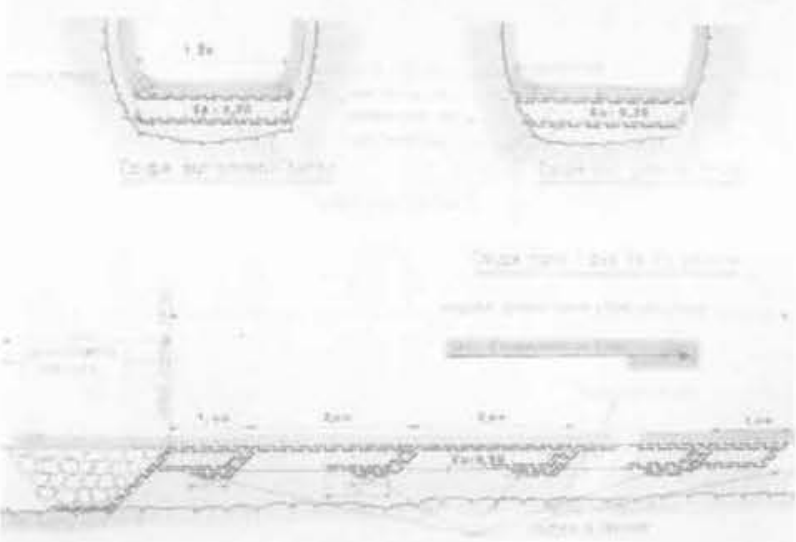

Photo 22

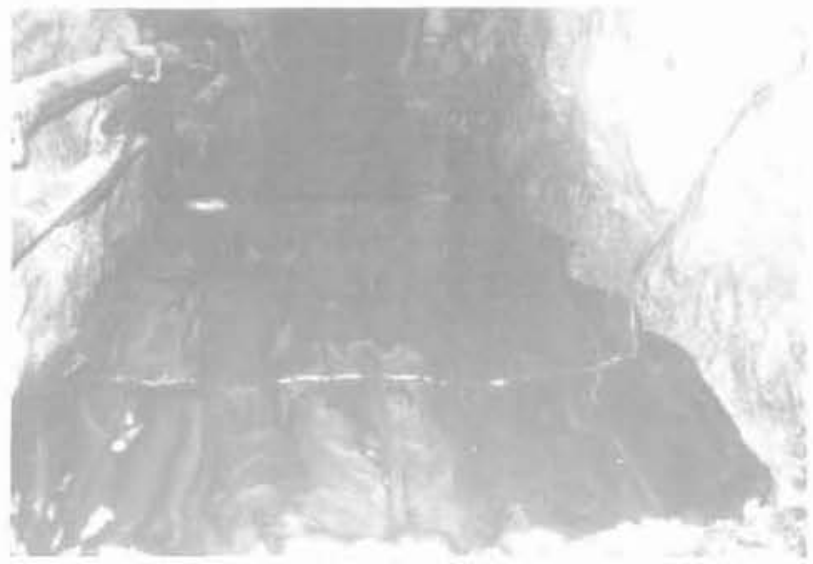

Photo 23

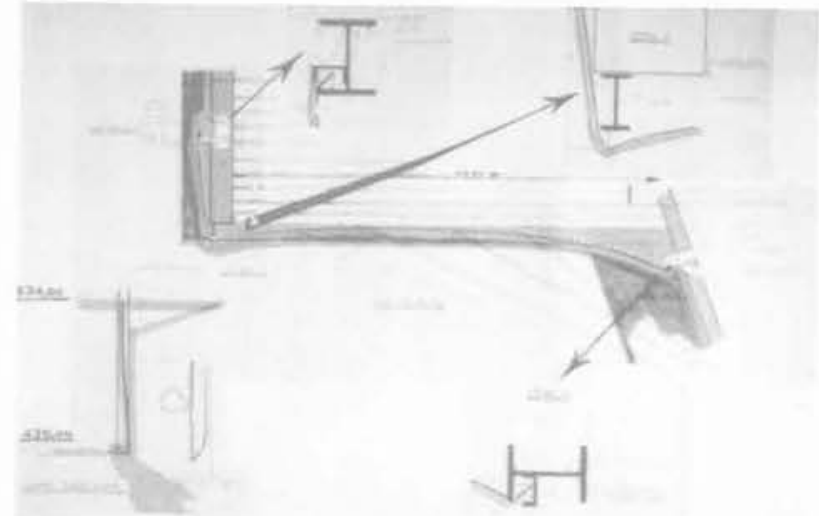

Photo 16
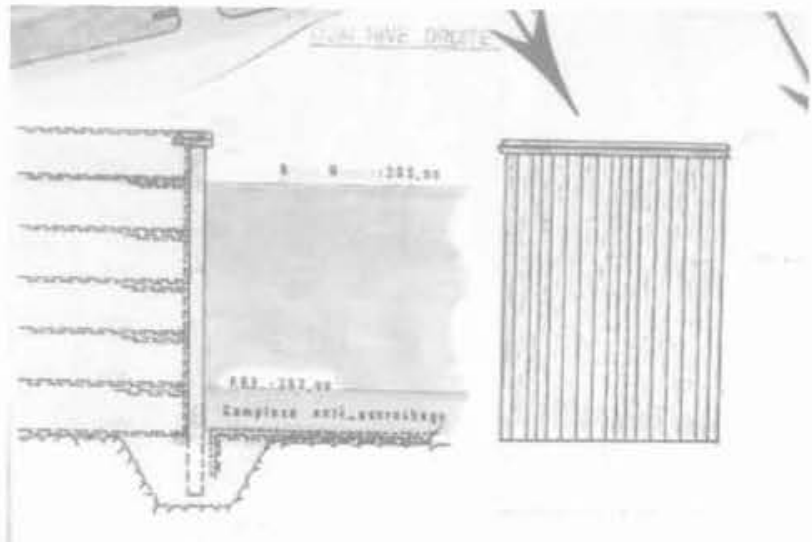

Photo 19

Lors de la vidange de la galerie hydroélectrique de Sovenzia (en Corse) où le radier n'était pas revêtu, il est apparu une érosion importante du marinage laissé en place avec déplacements et une érosion latérale sous les appuis des anneaux de soutènement béton réalisés par endroits (photo 21).

Une solution de gabions en tissus a été mise au point permettant dans une galerie de petite dimension un travail sans apport de matériaux lourds (photo 22).

Les photographies 23 et 24 montrent le revêtement en place dans chacune des structures non revêtues (23) et revêtues (24).

II s'agit là de quelques exemples dont les limites ne sont pas en vue. Nous nous retrouverons une fois très prochaine pour examiner d'autres utilisations des géotextiles.

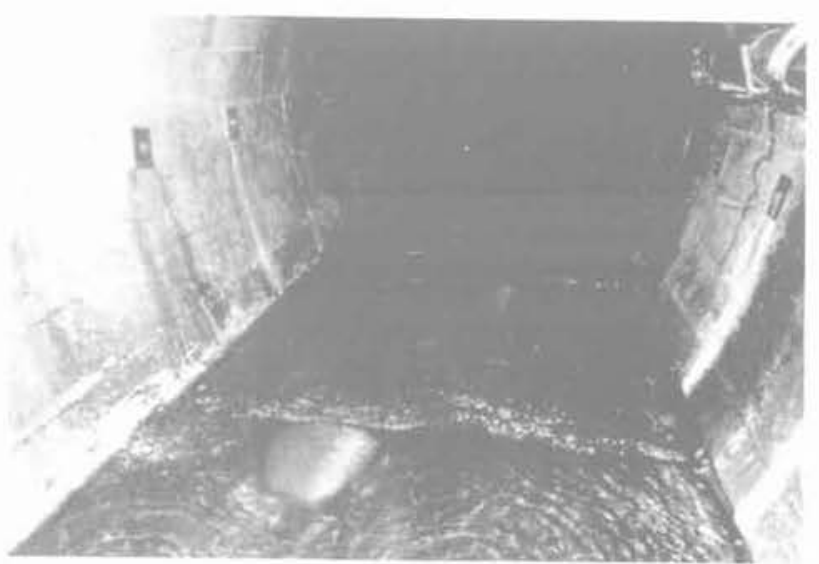

Photo 24 